\title{
Continuity and change in a qualitative longitudinal study of fatherhood: Relevance without responsibility
}

\begin{abstract}
Issues of time and change are foregrounded in qualitative longitudinal research $\left(\mathrm{QLL}^{1}\right)$ and are considered here in the context of contemporary fatherhood. From a wider sample of 46 men interviewed as part of the QLL Timescapes network, we draw on two case studies of men who became fathers for the first time in 2000 . This article considers the men's relationship to involvement and the linked concepts of exclusion and redundancy, terms which emerged from the data and changed over time in the men's accounts. We seek to emphasise the value of QLL methods for providing a more complex understanding of the lived experience of life transitions and their longer-term implications, contrasting this with existing studies offering a 'snapshot' approach.
\end{abstract}

Keywords: qualitative longitudinal research; fatherhood; transitions; involvement

\section{Introduction}

The model of 'new fatherhood' which emphasises fathers' active involvement in their children's lives has now ostensibly replaced more traditional versions to become the most culturally prevalent ideal (Dermott 2003). Although there has been some doubt over how contemporary this model actually is (La Rossa 1997), there has been increasing research interest in research years suggesting a discursive shift away from cultivating a public masculinity around work to creating a private masculinity around 
fathering (Mac an Ghaill and Haywood 2007). It has been argued that this represents a new hegemonic ideal of the involved father, willing and eager to engage in childcare (Johansson and Klinth 2008). The robust empirical finding that involvement has become an important aspect of being a good father according to men's own accounts has stimulated further questions about the experiences and meanings of contemporary fatherhood (Lupton and Barclay, 1997; Henwood and Procter 2003; Featherstone, 2009).

Our main aim in this article is methodological: to show how, by using qualitative longitudinal methodology, involved fatherhood can be investigated in fresh ways that foreground questions of time and change. The majority of qualitative studies about fatherhood are one off 'snapshots' (Neale and Flowerdew 2003) from a single interview or focus group with participants (such as Palkovitz et al. 2001, Dermott 2003, Johansson and Klinth 2008). Such studies have made significant contributions to the substantive literature on fatherhood, providing important insights into the concept of involvement. However they are embedded in a particular temporal moment and give little indication of how men may react differently to the discourse of involved fatherhood at other points in their life course.

According to Marsiglio et al's (2000:1179) review of fatherhood research in the 1990s, qualitative longitudinal methods are valuable in allowing for an 'understanding of the cultural context and interpersonal processes' and a richer analysis of "how fathers construct and negotiate their self-images as fathers and are directly and indirectly involved in their children's lives'. Similarly to Marsiglio, we have identified that, in contrast to data gathered solely at one point in time, a QLL 
design offers an opportunity to study fluctuations and changes in participants' accounts, so that it is possible to consider their ongoing, processual sense-making about their lived experiences of life transition, identities-in-the-making, and fatherhood. Our particular focus in this paper is to show how, through using QLL design, and studying continuities and changes in men's accounts and sense-making, we have been able to consider men's relationship to the cultural discourse of involved fatherhood and how this changes in relation to their lived experiences.

Qualitative longitudinal research is not a unitary methodology or method but, rather, addresses various possibilities for studying the contemporaneity of people's experiences of dynamic social worlds, as well as highlighting the importance of studying change over time for social science (Corden and Millar 2007a, Elliot et al. 2008). A key benefit of a QLL study is that data can be analysed at a particular point in time (across a wave of interviews with different participants) thus providing data on important issues across the sample. Furthermore QLL data can also be analysed over time using a case study approach to consider the account given by an individual over all waves of data collection, exploring how important themes emerge and play out. Elliot et al. (2008) refer to these two temporal dimensions as working diachronically, through time, and synchronically cross-cutting at one point in time. The articulation of the two is a particular challenge of QLL; in this paper we exemplify one way we have found of doing this.

Saldaña (2003) distinguishes between change over time; a before and after approach which emphasises discrete differences between 'then' and 'now', and change through time; illustrating the process of change and detailing the complexities 
of the journey. Consideration of change through time provides insight into how people organise their daily lives, and think about the past and future (Corden and Millar 2007b). In particular, longitudinal studies of transitions such as ours recognise that these are differentially experienced and interpreted, seeking to gain insight into 'the subjective experience of personal change' (Thomson et al. 2002:337). The longitudinal aspect of data collection allows the researcher to tailor interviews for each participant based on previous responses, gaining rich data as participants reflect back on their earlier thoughts (Farrall 2006). This type of reflexivity means that QLL studies can capture 'something of the process through which the self is made and remade over time' (McLeod and Thompson 2009:61), providing a more holistic understanding of why people act as they do (Neale et al. 2003).

Lewis (2007) suggests that the most evident type of change over time is narrative; the unfolding of individual stories across time. Lewis uses the term narrative to describe stories which are not told in a neatly linear way but are differently reinterpreted and recounted at different points in time. In this paper we consider the unfolding of individual stories through time, referring to the way in which different themes emerge and subside in participant accounts, rather than how the same experience is recounted at different points. A focus on individual stories suits a case study approach to illustrate change at the subjective level. Subsequent between-case comparisons, or placing cases into productive conversation with one another (Thomson 2007), can then illustrate differences in the nature of change and how it is articulated. In contrast to the analysis of data at one point in time, or taking a linear, before and after approach, following participants as they journey through time 
can provide a more dynamic sense of their changing identifications and the emergence of new influences on their thoughts and actions.

The data examined in the article are from a QLL study following men across the first eight years of fatherhood. Drawing on a social constructionist perspective to emphasise how the meaning of lives in progress is established in daily living (Holstein and Gubrium 2000), we consider participants' understandings of their lives and circumstances and how these may change through time (Elliott et al. 2008). This constructionist epistemology situates participants as meaning makers (Warren 2002) recognising that accounts are co-constructed during the interview encounter. The focus on participant interpretations is fostered by in-depth qualitative interviews, enabling researchers to grasp the internal logic and contextualised meanings of participants' life experiences and social worlds (Charmaz 2006, Henwood 2008). In this paper, issues of exclusion and redundancy - terms which emerged from the data are examined in terms of how they are made meaningful temporally using a case study approach. Here exclusion refers to feelings of being prevented from living an involved model of fatherhood that the men tended to imagine pre-birth, whilst redundancy features in future-oriented talk about the alleviation of direct parenting responsibilities when children become independent. After the presentation of data from two case studies we reflect on the connection between our methodological approach and findings, emphasising the additional detail and depth of data a QLL approach can provide. 


\section{The study}

In 2000 thirty expectant first-time fathers were qualitatively interviewed and then followed through into second, and in some cases third, interviews within the first year after the birth. Eighteen of these participants were re-interviewed as part of the Timescapes 'men as fathers' study sample when their children were eight years old ${ }^{2}$. Participants were aged between 20 and 40 years at the time of their first child's birth and in a range of relationship situations. Although there are a variety of occupations represented across the sample, a large proportion of men were in professional employment and identified as middle-class Whilst it is not unusual in social research for the sample to be skewed towards those who understand the educational endeavour of the research and seek to support it, we purposefully included those who were in more difficult circumstances and were less likely to come to us (Hemmerman 2010). The majority of participants were recruited through a newspaper advertisement seeking expectant fathers, and the men expressed interest in the interviews as an opportunity to explore their thoughts about fatherhood. The first three interviews were conducted by the same researcher, whilst eight years later participants spoke to one of two different researchers. The impact of researcher change and continuity is one that has merited discussion in relation to this study, leading to the conclusion that researcher discontinuity is not necessarily detrimental to our inquiry processes (Shirani, 2010).

The paper focuses on two case studies to provide examples of the men's divergent relationships to involvement and how this changes with their experiences of fatherhood. We consider the experiences of two men who exemplify characteristics of a significant proportion of the wider sample in terms of age and class position, yet 
offer different perspectives on issues relating to involvement. The two cases were selected due to the contrasting dynamics of continuity and change over time in the men's relationship to involvement, exclusion and redundancy, and because they were amongst those who talked most explicitly about these issues. Focussing on these two cases in detail enables us to illustrate the complexity of subjective experience QLL study can bring to the fore.

\section{Rick}

\section{Pre-birth}

Rick was 35 at the time of his first interview as an expectant father, working as an occupational therapist. He lived with his partner of one year, a company director. Rick had wanted to become a father for several years and was looking forward to impending fatherhood, anticipating a high level of involvement and equal sharing of employment and childcare responsibilities. Of all participants, Rick invested least in the idea of following traditional gender roles in relation to parenting, something he later reinforced through representing himself as the softer parent, in contrast to his partner as the tough disciplinarian. Those, like Rick, who occupied egalitarian gender roles in their relationships were more likely to anticipate high levels of involvement with their child post-birth. However, the pregnancy period was particularly problematic for these men as embodied experiences marked a dramatic gender separation, which contrasted with their otherwise equitable roles (Doucet 2007). In the first interview Rick articulated feelings of exclusion based on his detachment from the embodied experience of pregnancy, suggesting 'outsiderhood' (Draper 2003). Subsequently during their partner's pregnancy many of the men experienced a juxtaposition between expectations of involved fatherhood and the practical barriers 
they experienced to this. Whilst father involvement in pregnancy and birth is actively encouraged, this is a relatively new phenomenon with limited evidence of how this works in practice, unlike involvement post-birth. Like many of the other fathers Rick felt that health professionals did not seek to include him, leaving him feeling unable to raise concerns. Rick problematises the exclusion he experiences, reiterating the benefits his greater involvement could provide and emphasising the high levels of involvement he anticipates post-birth. Subsequently the pregnancy was positioned as a period of waiting based on expectancy (Adam 1990) as a relatively short phase of exclusion which the father can redeem through involvement with the baby at a later date. In this way Rick manages his exclusion by positioning it as a temporary phase.

\section{Post-birth}

The second interview took place when Rick's daughter was two months old. She had been born by caesarean and was being breastfed. Unexpectedly for Rick, his feelings of exclusion during pregnancy continued after the birth, initially with his daughter's brief stay in the special care unit. This experience was described as 'disempowering' as he was unable to care for his daughter in the highly involved way he had anticipated. On returning home Rick experienced new feelings of exclusion in relation to breastfeeding.

'Um things that I find difficult is not being able to stop that, not being able to stop her crying.... That's hard because I feel quite helpless you know when she is really screaming her head off. Then Tanya usually has to breastfeed her or sometimes she just likes to nurse on Tanya, on Tanya's breast just to fall off to sleep sort of thing. So that is difficult not being able to do anything about that, I can't feed her but I can't do anything.' 
The feelings of exclusion Rick experienced before the birth continued afterwards because of bodily exclusion from breastfeeding, making him feel 'helpless' that he 'can't do anything'. As with many of the fathers, Rick viewed breastfeeding as a privileged activity for forming a bond with the baby: valuing this more highly than other aspects of childcare (Jordan and Wall 1993). Therefore despite being an involved father who participated in all other aspects of childcare, Rick continued to feel marginalised. The post-birth interview illustrates how the exclusion he felt as an expectant father remained problematic in his account, particularly as he had not anticipated this continuing once the baby arrived.

In the second interview Rick was asked to reflect on his pre-birth responses about what constitutes a good father, and whether he had been able to be the sort of father he had wanted to be. Rick engages with this by reinvoking the forward-looking strategy he illustrated during pregnancy, continuing to suggest that he will be more involved in the future as his daughter grows up, at which stage she will no longer be physically dependent on her mother and therefore parenting roles can be more gender neutral.

'I feel that there is more to come. As Imogen develops I will develop my ability to be a father that will grow and evolve and develop with her.'

\section{Eight years later}

Eight years later Rick also had a second child. He continued to work in the same profession, whilst Tanya had given up work to become a stay-at-home parent. This had changed the balance of their relationship in terms of working and caring, reverting to a more traditional model of gender roles. This also meant that, as the sole 
earner, Rick was under increased pressure to provide for the family. When reminded of his earlier assertion that he would become more involved when his child was older, Rick agreed that this had happened, suggesting that increased involvement was pleasurable as his children became more autonomous and there was more he could do with them. However, he later indicates that the related increase in responsibility was not so welcome. Like many other fathers in the sample who in the early post-birth interviews were wishing the time away to a stage when they could be more involved, when this actually happened Rick did not appear content and remained futureoriented. Eight years later Rick talked about looking forward to a period in the future when his children would no longer need too much from him, desiring a time when he could make himself redundant. This desire for redundancy is in sharp contrast to the yearning for involvement he reports in earlier interviews.

\begin{abstract}
'you want them to become more and more mature as people so you can relate to them in a more adult to adult level and lose the kind of parenthood thing a bit. ...this is the bringing up kids part, phase, obviously that'll come to an end and they'll grow up hopefully and go their own ways, sort of preparing for that transition. I'm quite looking forward to it. Some people have this thing of being quite devastated when their children leave home and that they've lost their life purpose, I don't think so, I think I'll be quite looking forward to it (amusement) to doing something else you know'
\end{abstract}

Here Rick identifies parenting as a particular phase in his life course, one which can be defined by an ending when his children leave home. This clearly defined end is in sight for Rick as he anticipates the following stage to be one of freedom from responsibility, describing parenthood as a 'task' to get his children to adulthood, therefore seeing it as occupying a limited time period. Financial pressures were more acute for Rick than many of the other fathers; subsequently he may experience this responsibility as more challenging, motivating his desire for its alleviation. However his account suggests tensions as he does not want to be completely redundant. Rick describes how his oldest daughter is becoming 
increasingly independent and wanting less to do with her parents, which he finds hurtful. This desire for redundancy then is not about complete detachment from a relationship with the child, but rather alleviation of pressures of responsibility.

\section{QLL Reflections}

Rick's account moves from a desire for high levels of involvement in the early interviews through to looking forward to redundancy by round four. A common theme running throughout is his future-orientation; looking forward to a time which will be better than the present due to higher or lower levels of involvement. When asked directly about involvement Rick responded positively, emphasising the enjoyment he derived from the relationship with his children. The reflections about redundancy and exclusion emerged when discussing aspects of fatherhood he found difficult, and his thoughts about the future. That he did not raise the more negative aspects when asked about involvement suggests that Rick continues to uphold involved fatherhood as an ideal model at all stages, making it difficult to position himself in opposition to this. However a future-oriented strategy where he imagines a more positive situation suggests some dissatisfaction with his experience in the present. A QLL approach enables us to follow Rick's perception over time of the ideal of involvement, and consider the changes in relation to his family circumstances. For example becoming the sole earner by round four had made financial responsibility more of a pressing issue by this stage, whilst Rick was also more time-pressured due to greater involvement with his children. A one-off interview in the early stages of fatherhood may have indicated a man who saw only benefits from high levels of 
involvement, yet this fails to consider how his views change over time in relation to his lived experiences.

\section{Keith}

\section{Pre-birth}

Keith was 31 when he became a father for the first time. He was in professional employment as a research scientist whilst his wife had given up work indefinitely to be a stay-at-home parent. This rather traditional set-up led to clear distinctions in how parenting roles would be realised, suggesting childcare would not be divided equally. Although anticipating involvement in childcare, Keith saw his role as a father 'kicking in' later as his child grew up and they could enjoy shared activities. Keith felt his wife's direct physiological experience of pregnancy and breastfeeding would inevitably mean her having a stronger bond with the baby so the feelings of exclusion he encountered during pregnancy were natural and inevitable, something he had anticipated and expected to continue whilst the child was young. Therefore exclusion was not problematic for Keith in the same way that it troubled Rick.

Prior to the birth, when asked to think about his future fathering role, Keith articulated expectations of involved fathering and increased responsibility and was enthusiastic about these impending changes. However there were also some concerns, as in response to the interviewer's interest, he conveys more elaborated talk about dependency.

'Keith: I'm looking forward to the whole experience of being a father having someone that relies on you, is dependent on you... it's going to be really good to sort of look after it, take care and sort of bring it into the world ...

Interviewer: So is it important for you to feel depended on? Do you like that idea? 
Keith: I'd like to think that I can be there for Mary and for the baby, and they can rely on me, so in that positive sense, but I don't want it to feel as if I've got this pressure of them depending on me, and it doesn't feel like that and I don't think it will.'

Here Keith makes a subtle distinction between his desire to be seen as dependable and his apprehension about being depended on; whilst he wants his responsibilities recognised he does not want to feel the pressure of them. This is a theme he reiterates eight years later. Unlike Rick's clear desire for equal involvement, Keith positioned himself as taking an 'assistor' role (Gamble and Morse 1993) feeling that a bond would develop later in life when his child became more responsive and they could share interests. Like Rick he is future-oriented in thoughts about involvement, although he anticipated this occurring at a much later stage.

\section{Post-birth}

At interview two Keith had a two month old son born by caesarean who was being breastfed. Keith reiterated that breastfeeding was not something he felt excluded by, as his role was associated with more traditional ideal of breadwinning rather than involvement in all aspects of childcare.

'I mean I don't feel excluded in any way but I just feel somewhat guilty 'cause she does all the work ... it's not the case of feeling excluded but, erm, she's the one that suffers. She says "That's my job, you come home and bring the money" (amusement).... I think in the future I can see myself being a lot more, more involved and restore an equal balance but, and that's the way its gotta be at the moment so I'm okay with it.'

As in his pre-birth interview, Keith's traditional views rationalised his experience as something inevitable, postponing his involvement to a later stage of his son's life. Because his wife was also reported to hold similar views this did not apparently cause conflict. In contrast, as discussed above, Rick, who was in similar 
circumstances to Keith but held much less traditional ideas about gender roles and parenting, felt much more marginalised by his experience, suggesting that gender ideologies differentially conditioned the men's understandings and ways of experiencing fatherhood (Bulanda 2004).

Looking towards the future at the interviews two month's after the child's birth, participants across the sample unanimously anticipated increased involvement as their children got older, were less dependent on mothers and would be more responsive. The men were therefore able to project their conceptions of involved fatherhood into the future. Comments such as this from Keith were typical of our sample

'I want some feedback, I want response, and it's horrible to wish away his time but I'd like him to get older and bigger. That's what I'm looking forward to, the interaction and sort of teaching him things and telling him things.'

\section{Eight years later}

Eight years later Keith also had a second child. He continued to be the main breadwinner, although his wife had resumed part-time work, running her own retail business from the family home. In early interviews Keith suggested he would be more involved as his son got older, eight years later this seems to have been the case. Whilst Keith enjoyed increased involvement with his children, including reflecting back on his own childhood experiences and being able to share interests, this involvement was not problem-free. In his first interview Keith distinguished between being seen as dependable and being depended on, eight years later he still experienced this as a relevant distinction. In response to a question about how fatherhood had 
affected him personally, Keith suggests that the pressure of responsibility is currently felt and this motivates him to be forward looking to a time when it can be alleviated.

'I kind of think that's what my idea of a father is; to get to such a stage I'm not necessary almost. In some ways, you know, I prepare them for the world so they will be able to stand up on their own and cope with whatever life throws at them. So that would be my ideal goal I think; to make myself redundant. ... And then, and then, hopefully have a good relationship but rather than independent it's one of interaction, nice loving emotional interaction rather than just dependent on me (amusement).'

By planning for the future and compensating for what having children has constrained in the present, Keith justifies current difficulties as only a relatively short period in the biographical life course, minimising them as their end is in sight. The way in which Keith describes his experiences suggests that he sees his children's growing up years as a phase where he and his wife are required to suspend their own interests and time together. By emphasising that these things can be returned to in the future, Keith manages their lack in the present.

\section{QLL Reflections}

Keith was less invested in the involved father discourse than Rick, acknowledging from the beginning that his wife would take on the majority of childcare whilst he played an 'assistor' role. For the most part he was comfortable in early interviews with his detachment, as this reflected how the couple's roles would play out postbirth. However in the second interview he places more emphasis on the ideal of involved fatherhood, thinking about a time in the future when he could be more involved with his son. Eight years later he was more involved, yet Keith felt pressurised by the responsibilities of parenthood and, like Rick, looked forward to a time in the future when they could be alleviated. Although he did not have the same 
financial pressures as Rick, Keith experienced parenthood as incredibly demanding on his time, which could be difficult to reconcile with other aspects of his life.

\section{Concluding thoughts}

By considering themes of exclusion, involvement and redundancy as they evolve over time in the context of contemporary fatherhood, we have attended to the dynamics of men's subjective experiences and how they make sense of becoming and being fathers (Aitken, 2009). The data have been read as 'told stories'; the narrated personal life told through conversation (Squire 2008). The data presented therefore highlight the men's interpretations of their experiences, reflecting our social constructionist informed interviewing approach grounded in participants' understandings. The ways in which the ideal of involvement plays out practically in 'lived lives' (Squire 2008), with men becoming increasingly involved as their children grow up, has also been considered.

Using two case studies has enabled us to identify different routes through these major life course transitions, although many more patterns are indicated across the rest of our data. It has particularly illuminated important commonalities within the data regarding fathers' greater involvement over time, indicating that paternal involvement comes to feature more strongly later in the child's life. This paper is based on the experiences of resident fathers who remained in relationships with the mothers of their children throughout the course of the research. Experiences of exclusion and redundancy are often magnified for those fathers who are non-resident, 
have experienced relationship breakdown, and those who are involved in stepparenting. These are important issues warranting future consideration and discussion.

The concept of involvement with children as an important aspect of good fatherhood is upheld across all rounds of interviews; however, the way the men relate to it changes with their lived experiences and altered circumstances. Early on, involvement often remains an ideal as men are constrained by stark gender distinctions in relation to embodied experience. This is more problematic for those who anticipated equitable parenting and high involvement than for men who upheld more traditional gender distinctions. Eight years later these gendered barriers were no longer relevant and men could live out involved fatherhood. However, the negative aspects of this in terms of pressure experienced became more apparent in some of the men's accounts, and taking up a future orientation towards a time they viewed as preferable suggested some dissatisfaction with their lives in the present ${ }^{3}$. To articulate discomfort with responsibilities as a present feeling would be contentious, going against a contemporary discourse of parenthood which positions spending time with children as always pleasurable. By frequently showing amusement when describing a desire for redundancy, the men recognised this to be something they are not supposed to express. Future-oriented talk about alleviation of responsibility is a way for them to indicate their discomfort with the current demands placed on them, without incurring the possible negative consequences of explicitly verbalising this. This is because laughing, or positioning the talk as humorous, allows taboo subjects to be expressed in culturally permissible ways (Billig, 2005; Parkhill et al. forthcoming). In our study it is noteworthy how often reflections of more negative aspects of parenting are 
gleaned obliquely through responses to other questions, rather than discussed explicitly in the manner of more positive experiences.

As the accounts of Keith and Rick illustrate, some fathers adopted futureoriented approaches regardless of their child's gender. However, when asked about future fathering - particularly when their children reached adolescence - our participants were much more likely to express concerns about dealing with daughters at this age than with sons. Therefore whilst the child's gender did not appear to manifest itself when men expressed the desire for relevance without responsibility, it did inform participants' expectations of future fathering.

The paper touches on temporality as an important aspect of QLL data. In each interview participants were asked about their anticipated futures, responses which could then be followed up in later interviews when participants were asked to reflect back to see if their earlier expectations had been lived out. Participants also engaged with temporality in a variety of other ways, without explicit prompting to remind them of previous responses. Both Rick and Keith were future-oriented towards a time they imagined as preferable to their current situation, suggesting a linearity focussed on progression. In the wider research literature, this has been described as a masculine way of viewing temporality (Daly 1996). The apparent gendering of time use is, likewise, suggested by the men themselves in their accounts. However, whilst fathers feel, in line with social expectations, that they should spend time with their children (and overwhelmingly want to do so), their level of involvement is still seen as less obligatory in comparison to mothers. Hence, we believe that the conception of a masculine linear orientation should be problematised, an issue we consider elsewhere 
(Shirani and Henwood, submitted). Additionally, both case study fathers defined parenthood as a particular phase in the life course, relating this to age and generation. The unique contribution QLL can make to the production and analysis of temporal data is an issue that would benefit from further consideration, and is something our project, is engaging with further as part of the broader 'Timescapes' network ${ }^{4}$.

This type of analysis would not be possible without qualitative longitudinal research, showing the complexity of transitions and how they are differently experienced and interpreted by the people involved (Millar 2007). Indeed it might be useful to think of the entire period of fatherhood as a transition, a continuous passage, rather than the change from childless to parent (Draper 2003). Using this 'long view' (Thomson 2007) more complex and realistic understandings can be developed of individual lives, transitions and meaning making. This methodology has enabled us to follow up on themes of deferment introduced in earlier interviews through to redundancy appearing on the horizon in interview four, providing a more detailed, dynamic view of lived experiences of fatherhood, and respondents' thoughts and feelings about it, as it changes over the life course. These issues only become visible through a QLL design, which facilitates a temporal re-casting of experiences. The Timescapes ethos of walking alongside people through time as their lives unfold (Neale and Flowerdew, 2003) allows us to explore the temporal dimension of experience, based on a theorisation of the dynamic, processual element of human life (Holland et al. 2006).

Future research into how men deal with the impact of redundancy in their fathering role as their children reach adolescence and adulthood could further 
elucidate the lived experience of fatherhood, particularly in terms of gendered experiences of parenting. Research has begun to critically examine the extent to which the empty nest phenomenon (the emotional implications of children leaving home for their parents' lives) has relevance only to women (Ruszkowska, 2009), but has not considered the ways in which men's lives play out in relation to their anticipated trajectories. Adopting this, along with other temporal research strategies, would be of value, encouraging further questioning of the implications of conclusions drawn from 'snapshot' studies.

\section{Acknowledgement.}

Two Economic and Social Research Council Awards have supported the research reported in this article: Grant Nos: R02225016 and RES-347-25-0003. We thank the anonymous reviewers for their helpful guidance on an earlier version of the article.

\footnotetext{
${ }^{1}$ There is no standard shorthand to distinguish between qualitative and quantitative longitudinal study. QLL is used here (QuaL Longitudinal); its opposite would be QTL (QuanT Longitudinal).

2 The 'men as fathers' study also involves another cohort of 16 men from South Wales who became fathers in 2008, interviewed once before and twice after the birth.

${ }^{3}$ We do not suggest that a future orientation is always indicative of dissatisfaction with the present as other men in the sample noted their concerns about the future, or suggested that they would like their futures to continue in a similar way to their much-enjoyed present lifestyles. However we maintain that for the two case study fathers their future-orientation was a sign of dissatisfaction with the present, which was a reason why they were selected for discussion.

${ }^{4}$ http://www.timescapes.leeds.ac.uk/
}

\section{References}

Adam, B. (1990) Time and Social Theory. Cambridge: Polity

Aitken, S.C. (2009) The Awkward Spaces of Fathering. Farnham: Ashgate

Billig, M. (2005) Laughter and Ridicule: Towards a Social Critique of Humour.

\section{London:Sage}


Bulanda, R. (2004) Paternal Involvement with Children: The Influence of Gender Ideologies. Journal of Marriage and Family. 66 40-45

Charmaz, K (2006) Constructing Grounded Theory: A Practical Guide Through Qualitative Analysis. London: Sage

Corden, A. and Millar, J. (2007a) Qualitative Longitudinal Research for Social Policy - Introduction to Themed Section. Social Policy and Society. 6 (4) 529-532

Corden, A. and Millar, J. (2007b) Time and Change: A Review of the Qualitative Longitudinal Research Literature for Social Policy. Social Policy and Society. 6 (4) $583-592$

Daly, K. (1996) Families and Time: Keeping Pace in a Hurried Culture. California: Sage

Dermott, E. (2003) The 'Intimate Father': Defining Paternal Involvement. Sociological Research Online. 8 (4)

Doucet, A. (2007) Do Men Mother? Toronto: University of Toronto Press

Draper, J. (2003) Men's passage to fatherhood: an analysis of the contemporary relevance of transition theory. Nursing Inquiry 10 (1) 66-78 
Elliott, J. Holland, J. and Thompson, R. (2008) Longitudinal and Panel Studies. In Alasuutari, P. Bickman, L. and Brannen, J. (eds) $\underline{\text { Handbook of Social Research }}$ Methods. London: Sage

Farrall, S. What is Qualitative Longitudinal Research? London School of Economics and Political science Methodology Institute. Papers in Social Research

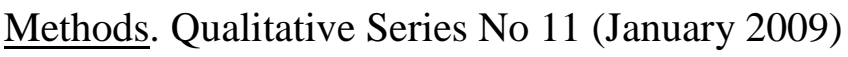

Featherstone, B. (2009) Contemporary Fathering :Theory, Policy and Practice The Policy Press

Gamble, D. and Morse, J. (1993) Fathers of Breastfed Infants: Postponing and Types of Involvement. Journal of Obstetric, Gynecologic and Neonatal Nursing. 22 (4) $358-369$

Hemmerman, L. (2010) Researching the Hard to Reach and the Hard to Keep: Notes from the Field on Longitudinal Sample Maintenance. In Shirani, F. and Weller, S. (eds) Timescapes Working Paper Series No.2. Conducting Qualitative Longitudinal Research: Fieldwork Experiences. ISSN: 17583349

Henwood, K. (2008) Qualitative Research, Reflexivity and Living with Risk: Valuing and Practicing Epistemic Reflexivity and Centering Marginality. Qualitative Research in Psychology. 5 45-55 
Henwood, K. and Procter, J. (2003) The 'good father': Reading men's accounts of paternal involvement during the transition to first-time fatherhood. British Journal of Social Psychology 42 (3) 337-355

Holland, J. Thompson, R. and Henderson, S. (2006) Qualitative Longitudinal Research: A Discussion Paper. Families and Social Capital ESRC Research Group Working Paper No. 21

Holstein, J. and Gubrium, J. (2000) Constructing the Life Course: Second Edition. New York: General Hall

Johansson, T. and Klinth, R. (2008) Caring Fathers: The Ideology of Gender Equality and Masculine Positions. Men and Masculinities 11(1) 42-62

Jordan, P. and Wall, V. (1993) Supporting the Father When an Infant is Breastfed. Journal of Human Lactation. 9, 1, pp31-34

La Rossa, R. (1997) The Modernization of Fatherhood: A Social and Political History. London: University of Chicago Press.

Lewis, J. (2007) Analysing Qualitative Longitudinal Research in Evaluations. Social Policy and Society. 6 (4) 545-556

Lupton, D. and Barclay, D. (1997) Constructing Fatherhood: Discourses and Experiences London: Sage 
Mac an Ghaill, M. and Haywood, C. (2007) Gender, Culture and Society: Contemporary Masculinities and Femininities. Basingstoke: Palgrave Macmillan

Marsiglio, W. Amato, P. Day, R. Lamb, M. (2000) Scholarship on Fatherhood in the 1990s and Beyond. Journal of Marriage and Family. 62(4) 1173-1191

McLeod, J. and Thomson, R. (2009) Researching Social Change. London: Sage.

Millar, J. (2007) The Dynamics of Poverty and Employment: The Contribution of Qualitative Longitudinal Research to Understanding Transitions, Adaptations and Trajectories. Social Policy and Society. 6 (4) 533-544

Neale, B. and Flowerdew, J. (2003) Time, texture and childhood: the contours of longitudinal qualitative research. International Journal of Social Research Methodology. 6 (3) 189-199

Neale, B. Flowerdew, J. Smart, C. and Wade, A. (2003) Enduring Families? Children's Long Term Reflections on Post Divorce Family Life. Research report for ESRC (No. R000239248)

Palkovitz, R. Copes. M. and Woolfolk, T. "It's Like....You Discover a New Sense of Being": Involved Fathering as an Evoker of Adult Development. Men and Masculinities (July 2001) 4, 1, pp49-69 
Parkhill, K, Henwood, K.L., Pidgeon, N. and Simmons, P.(submitted) .Laughing it off? Disentangling the meanings of humour in a UK study of living with nuclear risk.

Ruszkowska, J. T. (2009) Constructions of Fatherhood during the Transitions to Empty Nest Stage of Parenting Nottingham Trent University, Unpublished $\mathrm{PhD}$ Thesis

Saldaña, J. (2003) Longitudinal Qualitative Research: Analyzing Change Through Time. Walnut Creek CA: AltaMira

Shirani, F. (2010) Researcher change and continuity in a qualitative longitudinal study. In Shirani, F. and Weller, S. (eds) Timescapes Working Paper Series No.2. Conducting Qualitative Longitudinal Research: Fieldwork Experiences. ISSN: 17583349

Shirani, F. and Henwood, K. Taking One Day at a Time: Temporal experiences in the context of unexpected life course transitions (forthcoming)

Squire, C. (2008) Approaches to Narrative Research. ESRC National Centre for Research Methods Review Paper. NCRM 009 
Thomson, R. (2007) The Qualitative Longitudinal Case History: Practical, Methodological and Ethical Reflections. Social Policy and Society. 6 (4) 571582

Thomson, R. Bell, R. Holland, J. Henderson, S. McGrellis, S. and Sharpe, S. (2002) Critical Moments: Choice, Chance and Opportunity in Young People's Narratives of Transition. Sociology 36 (2) 335-354

Warren, C.A.B. (2002) Qualitative Interviewing. In Gubrium, J. and Holstein, J. (eds) Handbook of Interview Research. Thousand Oaks CA: Sage 